\title{
UNA INTERPRETACIÓN DE VIAJE AL REINO DE LOS DESEOS, A LA LUZ DE TRES MITOS: GÉNESIS Y APOCALIPSIS, EL MUNDO AL REVÉS, LA JOVEN VIEJA
}

\author{
Sonia Quesada Sánchez
}

\begin{abstract}
The analysis that is proposed in this article is based on the theorical propositions of the sociocriticism. We will try to study the project of writting from the borrowings that Viaje al reino de los deseos takes from others and whose distribution and working makes sense.
\end{abstract}

\section{Génesis y Apocalipsis claves en el proyecto de escritura}

El presente artículo analiza la intertextualidad en Viaje al reino de los deseos, como interpretación del mundo actual. Centramos nuestro estudio en tres mitos básicos: Génesis y Apocalipsis, el Mundo al Revés y la Joven Vieja.

Edmond Cros, en Literatura, ideología y sociedad, se refiere al mito del Génesis como un texto sagrado, que se presenta en su origen como fundamento de cierto tipo de espiritualidad. Sin embargo, al referirse a su análisis sobre "Ciudadano Kane", apunta lo siguiente:

La presencia de este texto y sus modalidades de desconstrucción denuncian en la organización de esta nueva Arca de Noé la ausencia de toda referencia a Dios. (Cros 1986: 56).

Hacemos esta referencia de Cros, por cuanto la misma sirve a nuestra reflexión sobre los intertextos bíblicos del Génesis y del Apocalipsis y el alejamiento que los mismos impulsan en Viaje al reino de los deseos, en relación con la instancia de la divinidad. Sin embargo, la sustancia significante se mantiene en ambos casos en cuanto a la significación sagrada de su origen: el Génesis, como creación y el Apocalipsis, como destrucción.

Consideramos que, en Viaje al reino de los deseos, son claves para el análisis del funcionamiento de dichos intertextos en el centro programador y generador del porvenir del texto.

El universo novelesco de Viaje al reino de los deseos estará marcado de manera recurrente por las huellas de los dos textos bíblicos citados, y no por casualidad, ya que, como lo expresamos anteriormente, el texto va produciendo una programación de la escritura a la que es posible acceder mediante este trabajo sobre la intertextualidad. 


\subsection{Génesis intertexto de apertura}

Veamos el párrafo II, inicio del capítulo 6, cuando Orellabac descubre un huevo enorme, cúbico y sin fisuras y se dirige hacia él, momento en que ocurre lo siguiente:

De repente temblaron los aires, se agitó el agua, una sombra tan voraz como la noche oscureció los cielos. (Herra 1992: 56)

Esta descripción corresponde al momento en que el ave extraordinaria empolla el huevo, de donde nacerá Acayú, el Pájaro de la Dicha . A su vez, la cita remite de inmediato al Génesis en su I parte: La creación, donde se relata la forma como Dios comenzó la creación del cielo y la tierra.

En Viaje al reino de los deseos, la creación de Acayú, el Pájaro de la Dicha, corresponde al intertexto bíblico y se inserta en Viaje al reino de los deseos con la misma significación de nacimiento, creación, construcción, pero sin la mano divina que se advierte en el texto sagrado.

Lo que resulta aún más interesante de la cita es su doble funcionamiento en el sentido en que, además de la creación de Acayú, Orellabac inicia una nueva vida. Posteriormente, este personaje lo ayudará a salir de Dabuic, para empezar así lo que será su viaje hacia el reino de los deseos.

Nacimiento de Acayú, creación y renacimiento de Orellabac son dos aspectos que se desprenden del funcionamiento del Génesis como intertexto en Viaje al reino de los deseos y que se enmarcan dentro del eje estructurante de la construcción-deconstrucción.

Siguiendo la huella del mismo intertexto bíblico, encontramos otro sintagma de este: "El hombre en el Jardín del Edén", texto que explica en la Biblia la forma cómo se gesta el primer hombre creado por Dios:

Después, Dios el Señor plantó un jardín en la región de Edén (...) Hizo crecer también toda clase de árboles hermosos que daban fruto bueno para comer. En medio del jardín puso también el árbol de la vida y el árbol del conocimiento del bien y del mal. (Biblia 1979: 3)

En Viaje al reino de los deseos, al describir la llegada de Oreliabac al Jardín del Olvido; leemos lo siguiente:

Llegamos a un valle luminoso, irrigado por riachuelos. Era verde, verde claro y verde sombrío. A lo lejos se extendía un huerto con todas las frutas posibles. Y, en el centro, se mecía con la brisa un gran árbol de frutas rojas donde vivía enroscado un gusano. (Herra 1992: 56)

Es evidente el préstamo que Viaje al reino de los deseos hace al texto sagrado y la función que desempeña en el relato. El Génesis es el inicio de todo, del cielo, la tierra y del hombre y subraya ese don de la divinidad y la posibilidad que le ofrece al hombre de sobrevivir en un lugar donde encuentre todo lo deseado.

Viaje al reino de los deseos ubica al personaje en el Jardín del Olvido como inicio de lo que podría ser una nueva vida, o al menos, de una nueva aventura. Asimismo, participan de la 
disyuntiva en que ambos personajes, el primer hombre y Orellabac, que también es el primer hombre metálico, han de confrontarse; ambos deben decidir si se quedan en ese lugar privilegiado en que han sido colocados o buscan la forma de salir o ser expulsados. Sin embargo, en ambos casos se trata de un hacerse o construirse a partir de esa oportunidad ofrecida a ambos personajes.

De esta manera, la intertextualidad que se produce del Génesis en el nuevo texto está marcada por las nociones de creación, construcción, nacimiento, nueva vida, lo cual, a su vez, producirá una contraposición interesante con el otro texto implicado, el Apocalipsis, y cuya recurrencia en el nuevo texto es mayor que la del primero.

\subsection{Apocalipsis y destrucción}

Cabe señalar que uno de los momentos más claros en cuanto al proceso de destrucción en Viaje al reino de los deseos se presenta cuando Orellabac, impresionado por la doncella del palacio de cristal, olvida la advertencia de Acayú y emite un sonido dentro del lugar, lo cual tiene como consecuencia lo siguiente:

Pero también fue un crujir de cristales rotos (...) Los ecos fueron triturando cristales, los cristales cayeron con estrépito (...) Las torres se desmoronaron emitiendo quejidos de materia viva. (Herra 1992: 52)

En el texto bíblico, Apocalipsis 16-19, encontramos lo siguiente:

La gran ciudad se partió en tres y las ciudades del mundo se derrumbaron.

(Biblia 1979: 371)

La primera cita se refiere a la caída del castillo que encierra la doncella del Castillo de Cristal y que Orellabac debe despertar con un beso; sin embargo, en su arrebato de gritar: ¡Qué bella es!, produce la destrucción que se describe y hace que los piratas que lo acompañan en esta aventura huyan. La segunda cita del Apocalipsis está tomada de la Biblia, capítulo 16, versículo 16, y reproduce la destrucción humana y material.

En ambos casos, tal como puede observarse, la sustancia del significante se concentra en la destrucción y especialmente, en la destrucción material, lo cual nos permite afirmar que, del mismo modo como el Génesis marca la creación, la nueva vida; el Apocalipsis, se inserta en el nuevo texto como la marca de la destrucción y, por lo tanto, de la muerte.

lo siguiente:

En esa recurrencia del texto apocalíptico en Viaje al reino de los deseos, encontramos

El cielo rojo, sin nubes, ardía. El caballero siguió su marcha (...) No anochecía ni dejaba de restallar el cielo. (Herra 1992: 143)

En la Biblia, leemos: 
Se le dio al sol poder para quemar con fuego a la gente y todos quedaron terriblemente quemados. (Biblia 1979: 371)

La primera cita se refiere al camino que lleva a Orellabac hasta Tenebrante, donde deberá rescatar a la doncella Dulceluz de la prisión en que la tiene su padrastro. En otras palabras, Orellabac va hacia su destrucción, su muerte.

En la segunda cita estamos ante las palabras bíblicas que visualizan la destrucción del universo y los castigos que los hombres sufrirán por culpa de sus pecados. El elemento determinante en ambos casos es el fuego como purificador.

Esta aventura de Orellabac lo acerca al caos que se produce en el universo novelesco de la siguiente manera:

Detrás de la grieta se abría un espacio ilimitado como la esfera celeste, pero vagamente luminoso y sin estrellas. Había puntos, líneas, elipsis, parábolas, rombos, cubos, esferas, prismas, trapecios, y todos los paralelípedos imaginables. (Herra 1992: 145)

Con esta última cita de Viaje al reino de los deseos agregamos un elemento más a la interpretación del intertexto bíblico, el caos y el desorden. Así, caos, destrucción y muerte son los tres elementos que caracterizan el Apocalipsis y que cobran fuerza en su significación, al ser acogidos por el nuevo texto con la misma carga semántica que en la del texto antiguo.

Viaje al reino de los deseos se inicia con la creación-construcción del caballero andante Orellabac y culminará con la muerte-destrucción de este; mediante una descripción apocalíptica caracterizada por la destrucción y la muerte. En este mismo sentido, culminará la vida de Orellabac, cuando en su última aventura se enfrenta a los cazahierro:

Saltaron y le hundieron los dientes de clavo y dagas centellantes, masticaron la armadura, la hoja de la espalda negra, el yermo, degustando y destruyendo con placer de engranaje, y luego le clavaron los dientes en el cuerpo y le chuparon el líquido rojo que derramaba a chorros. (Herra 1992: 212)

En esta última aventura de Orellabac, encontrará el caos, la destrucción y la muerte con que se vierte en Viaje al reino de los deseos el Apocalipsis.

Como hemos podido observar, tanto la recurrencia del Génesis como la del Apocalipsis, son espacios de lectura susceptibles de interpretarse como puntos de anclaje en el proceso de escritura de Viaje al reino de los deseos.

Si tomamos en cuenta la propuesta de Edmond Cros:

No es una antigua textualidad la que va a desconstruirse en la nueva, sino de alguna forma cierta manera de leer este primer texto. (Cros 1986: 101-2)

Por lo tanto, no existe en el texto un simbolismo de tipo religioso al que podríamos acogernos rápidamente, sino, la interpretación de una posible destrucción del hombre y la sociedad actuales, a la luz de una serie de fenómenos ideológicos, sociales, económicos y 
culturales que, de algún modo, hacen que el hombre del siglo XX pueda perder su propia perspectiva y se oriente hacia su propia destrucción.

\subsection{Génesis y Apocalipsis decodificadores}

El texto nos sitúa en una disyunción correlativa, construcción-creación y destrucciónmuerte. A su vez el texto mismo ofrece la clave de su decodificación como indicio del trayecto de escritura y de la programación de lectura.

Tratemos de esquematizarlo de la siguiente manera:

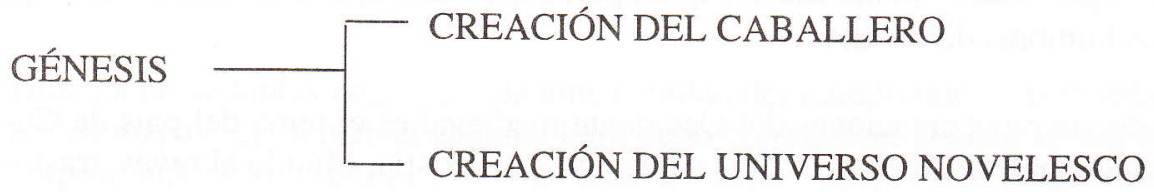

APOCALIPSIS -

Podríamos, a partir de este esquema, retomar la propuesta de E. Cros, cuando manifiesta que "al mismo tiempo que el texto se instituye, organiza los puntos de referencia ideológica que permitirán leerlo" (Cros 1992: 100). Con lo cual insistimos nuevamente en el sentido de que el texto se orienta y orienta un cierto modo de leerlo, al reproducir sistemáticamente la pulsión vida-muerte, señalada anteriormente.

Por lo tanto, Viaje al reino de los deseos es el espacio discursivo capaz de releer esos intertextos a la luz de los albores del siglo XXI. Cabe retomar aquí la propuesta de M. Foucault, sobre el ritual de la circunstancia, en cuanto a las condiciones históricas de posibilidad de emergencia del objeto del discurso:

No se puede hablar en cualquier época de cualquier cosa. (Cros 1986: 60)

Así, Viaje al reino de los deseos es un texto que relee la problemática relación del hombre y la sociedad, en la última década del siglo XX, cibernetizado y deshumanizado; en una sociedad como la costarricense, en la que no es común, ni en sus prácticas sociales, ni en sus prácticas discursivas, encontrar este tipo de manifestaciones. Esta lectura de la realidad actual la hace Viaje al reino de los deseos a la luz de esos mitos que sirven de marco a una reflexión contemporánea. 
Viaje al reino de los deseos interpreta el mundo actual a la luz de una serie de intertextos de la antigüedad.

\section{El mundo al revés en Viaje al reino de los deseos, una interpretación del mundo actual}

\subsection{El mundo al revés y las épocas de transición}

Según Jacques Le Goff, uno de los grandes temas y fuerzas mentales de la Edad Media, con dominio del folclore y de lo maravilloso, es el tópico del mundo al revés, que aparece en el siglo XIII. Es significativo como indicio que aparezca en una época de transición y que, según él, marca a los hombres del medioevo:

Una de las raras creaciones del Occidente medieval es el tema del país de $\mathrm{Cu}$ caña que aparece en el siglo XIII y que antes no existía. Mundo al revés, trastocado. (Jacques Le Goff 1986: 7)

Esa manifestación del pensamiento medieval occidental en el tópico del mundo al revés es reveladora del caos y la inestabilidad de los hombres de una época, caracterizada por problemas de orden político, religioso, económico y cultural. Este tópico traduce la angustiosa búsqueda de los hombres en un mundo que se abocaba hacia transformaciones de diversa índole y que son experimentadas y profetizadas por los hombres.

Edmond Cros en Literatura, ideología y sociedad, en su capítulo sobre el funcionamiento de las instituciones ideológicas en La hora de todos de Quevedo, realiza un análisis profundo sobre el funcionamiento de dicho tópico y acota que:

En el caso que nos interesa, este "ya dicho", lo sabemos, es un tópico, el del "mundus inversus" transhistórico y transcultural. (Cros 1986: 215)

Este análisis sobre La hora de todos lo lleva a plantearse algunos aspectos, que nos parece muy importante rescatar, por su relación con nuestro estudio; entre otros, los siguientes:

Es grande la tentación de interrogar el mismo tópico para reconocer en él la coexistencia, por una parte, de un sistema de ocultación de este mismo discurso. (Cros 1986:216)

\subsection{Un mundo al revés: texto de subversión}

De la misma manera, este tópico se vierte en Viaje al reino de los deseos como forma de transgresión y subversión como rompimiento, pero a la vez como percepción de la sociedad actual. Lo que se sustenta en la referencia que hace Cros de J. A. Maraval, quien manifiesta sobre el sentimiento de crisis lo siguiente: 
Pero lo cierto es que desde que aparece lleno de conquistas sobre la naturaleza y de novedades sobre la sociedad el tipo que hemos dado en llamar hombre moderno, empieza también a desarrollarse en él el comprender que las cosas de la economía quizá principalmente y también de otros ramos de la vida colectiva no andan bien y, lo que es más importante, a pensar que podrían ir mejor... (Cros 1986: 218)

Este sentimiento de crisis es claramente perceptible en el funcionamiento del tópico sobre el mundo al revés en Viaje al reino de los deseos, de tal manera que se resemantiza en el nuevo texto en dos dimensiones, por una parte, como discurso subversivo, y, por otra parte, como discurso reflexivo sobre el desarrollo de la sociedad y el hombre moderno. Veamos algunos ejemplos:

Una noche de tantas llegamos a la única ciudad del mundo que no está señalada en los mapas. La llamaban Daduic. Pero debo corregirme: Daduic sí está en los mapas, aunque solo por el reverso, dándole vuelta al papel o al pergamino. En las ciudades al revés, como Daduic, que sólo pueden dibujarse detrás de los mapas, casi todo sucede, existe y se piensa a la inversa del resto de las cuidades y de los países. (Herra 1992:16)

De esta manera, acoge el tópico Viaje al reino de los deseos, a cuya evolución hace referencia Le Goff, mediante un recuento histórico en el que señala una serie de diferentes momentos en los que se ha convocado este tópico. Según dicho estudio, el cual asumimos para nuestra investigación:

En El espejo de los necios (escrito antes de 1180) Nigelo Wireker nos hace ver cómo el tiempo presente pone de cabeza todo el pasado. Hacia 1185 Alain de Lille describe, en su Anticlaudiano, el bosque de la Fortuna, en vez de árboles copudos hay matorrales, en lugar del ruiseñor canta la alondra. En el Architrenius de Juan de Hanovelle, el escenario del mundo al revés, el monte de Presunción, ahí vuela la tortuga, la liebre amenaza al león. (Le Goff 1986: 147148-149)

Uno de los motivos que podemos observar en esta cita es la visión de un presente que desorganiza el pasado y visualiza, de manera caótica, el mundo, de manera que hechos y seres se perciben en actividades contrarias e imprevisibles y por lo tanto, opuestas a nuestra percepción de un mundo "al derecho".

Le Goff cita, además, el poema de Théophile de Viau (1626), y cuya visión de mundo halló con en el surrealismo de la tercera década de nuestro siglo:

Le ruisseau remonte en sa source un boeuf gravit sur un clocher; le sang coule de ce rocher; un aspic s'occouple d'une ourse, sur le haut d'une vielle tour un serpent des chire un vautour; le feu brusle dedans la glace, le soleil est devenu noir. Je voy la lune qui va cheoir cit arbre est sorty de sa place. (Le Goff 1986:147) 
Este poema refuerza el motivo de la desorganización, anarquía y caos en el mundo, mediante acciones de animales y objetos que funcionan contrariamente a lo esperado.

\subsection{Daduic, una ciudad al revés, en un mundo al revés}

Resulta muy significativo que en Viaje al reino de los deseos sea Daduic el primer espacio en la diégesis del relato y que tal y como se observara gracias a la cita, está marcado por el caos y lo imprevisible. Podemos resumir la singularidad que caracteriza a Daduic, que es "ciudad" al revés, en las siguientes observaciones:

1. Daduic es el lugar donde se inicia la diégesis, aunque no existe en los mapas.

2. Es donde el caballero recibe por nombre Orellabac.

3. Es un lugar donde nadie quiere gobernar y por lo tanto, un grupo de daduicianos ruega al más vil de los hombres que asuma el poder, pero él se niega.

4. Es el lugar donde habita la Joven Vieja (en el campanario), la misma que condena a Orellabac a encontrar el libro de los deseos.

Además se caracteriza por lo siguiente:

En relación con el lenguaje:

En Daduic se hablaba al revés, es decir, comenzando las frases por el final. (Herra 1992: 16)

En cuanto al comportamiento de seres y objetos:

Se caminaba de manos, los espejos reflejaban caras desconocidas, los lagartos volaban junto a los zorros por los cielos, las grandes raíces de los árboles se hinchaban hacia arriba. Los frutos brotaban de la tierra. Las mariposas perseguían a los perros. Los ratones asustaban a los gatos. (Herra 1992: 17)

Es en este lugar donde el caballero escucha por primera vez su nombre:

Escuché una voz y tres veces el mismo grito: ¡Orellabac, Orellabac, Orellabac! Era un caminante que caminaba de manos. (Herra 1992: 17)

\subsection{El presente pone de cabeza todo el pasado}

Las citas anteriores y las observaciones que hace Le Goff en torno a la evolución de este tópico confirman que Viaje al reino de los deseos acoge el tópico del mundo al revés con toda la carga semántica que éste ha arrastrado a lo largo de la historia, especialmente, en cuanto a que "el presente pone de cabeza todo el pasado". Es ese precisamente el sentido que se vierte en el nuevo texto, en el cual se presenta una enumeración detallada de diferentes lugares y seres que proceden al revés y que, conforme transcurre el relato, se comportan de manera caótica. 
En Viaje al reino de los deseos, se alude además a los problemas de orden político que también andan al revés, pues ya en Daduic, nadie quiere gobernar, los daduicianos declinan el poder político y, contrariamente a lo esperado, designan al más vil de ellos para que los gobierne:

El más vil de los daduicianos gritaba: "Los que no tienen nada carecen de aduladores. Yo no quiero aduladores. Dejadme". El más vil de los daduicianos volvió a gritar: "Yo no quiero ser gobernante, no quiero que me chupen los pies". (Herra 1992: 19)

La cita muestra el punto de vista de la instancia narrativa en relación con el tópico, trascendiendo hasta las fronteras de lo político en clara contraposición con el ansia de poder y las fervientes luchas que se llevan a cabo en nuestros países y en muchos otros del mundo, por llegar a gobernar. Sin embargo, en Daduic el deseo de acceder al poder, queda reducido al grado más bajo en la jerarquía de valores de dicha sociedad.

Es evidente que este intertexto muestra un punto de vista contemporáneo a la luz de un intertexto del pasado que visualiza la situación caótica y de inestabilidad, producto del encuentro de las nuevas con las viejas formas de pensamiento.

Así, Viaje al reino de los deseos reproduce ese espacio de tensiones en que ambos coexisten, en una clara resemantización del pasado en un presente al revés.

\section{La disyunción presente-pasado en el mito de la anciana moza}

\subsection{El mito de la anciana moza y las épocas de transición}

Ernest Robert Curtius, al referirse al tópico de la Anciana Moza, lo relaciona con épocas de transición, cuando para los hombres, los seres ideales forman parte de su mundo. Este tópico advierte el paso de los viejos a los nuevos tiempos, de lo antiguo a lo moderno o de su coexistencia en épocas de crisis.

Al releer este intertexto, Viaje al reino de los deseos ofrece la recurrencia del tópico en épocas de transición y crisis. Desde este punto de vista, el funcionamiento de la Anciana Moza posee una gran fuerza en la dinámica de la diégesis, ya que es determinante para todo el porvenir del texto. El símbolo de la vejez y la juventud reunidas en un solo ser, reproducen en el texto la coexistencia de lo antiguo y lo moderno. En Viaje al reino de los deseos es, además, un ser extraordinario, sobrenatural y ambivalente.

Curtius al referirse a este tópico lo plantea así:

La relación entre la juventud y el paso de una a otra se empleó también en la caracterización de imágenes femeninas e ideales que a menudo son algo más que meras abstracciones personificadas. La sorprendente frecuencia de estas figuras en la antigüedad tardía (tanto en autores paganos como en los cristianos), no es solo una moda; si llegaron a hacerse tan comunes es porque los hombres 
de aquellos siglos de transición concebían realmente a estos seres ideales como parte esencial de su mundo anímico. (Ernest Robert Curtius 1975: 49)

El que este tópico haya sido recurrente en momentos de transición nos parece clave en la intertextualidad de Viaje al reino de los deseos, porque ofrece una vez más un indicio programador de lectura y de trayectos de sentido, congruentes con los otros intertextos analizados anteriormente.

Jacques Le Goff, siguiendo la huella discursiva en la evolución histórica de este tópico, cita una serie de ejemplos que van desde el año 300 hasta el siglo XIX, en que el tópico de la Joven Vieja se ha reproducido (Le Goff 1986: 155-7). Cita a Boecio, para quien la Filosofía tiene figura de noble matrona que reboza de fuerza vital, a pesar de su avanzadísima edad. Se refiere también a la obra de Virgilio, a Claudiano y otros, hasta llegar a la obra juvenil de Balzac, en que aparecen figuras alegóricas que personifican ciertos poderes que luchan por conquistar la nueva Era.

Para concluir, Le Goff se refiere al cuento "Jesús-Christ en Flandre" (1831), en que la Iglesia aparece como una anciana desdentada y calva; el soñador le pregunta: "¿Qué has hecho de bueno?", y en ese momento se produce la transformación:

La viejecita se erguió, sacudiendo sus harapos, creció, se iluminó, sonrió, salió de su negra crisálida. (Le Goff 1986: 157)

En todos los casos citados, el motivo recurrente a través de la historia es el remozamiento que sufre lo viejo ante el aliciente que le produce lo nuevo.

\subsection{El mito de la Anciana Moza y la Joven Vieja}

En Viaje al reino de los deseos, la Joven Vieja funciona con las mismas características; se encuentra en la ciudad al revés, habita en el campanario. Además, su ira por la llegada de Orellabac a Daduic, radica en que éste mancilla su juventud, pues llega precisamente el día que coincide con el solsticio y las mil lunas de su nacimiento:

Recuerdo a la Joven Vieja mientras bailaba colgada a las cuerdas tensas, desapareciendo y reapareciendo de frente o de espaldas. (Herra 1992: 21)

"Te has hecho digno de un delito", -exclamó con gritos dulces y aterradores. "Soy legisladora y verdugo. Yo vine a este mundo hace mil lunas. El día de hoy mancillaste mi juventud. Tu llegada coincide con el solsticio y las mil lunas de mi nacimiento. Estas coincidencias delictivas se premian en Daduic". (Herra 1992: 22)

La coexistencia en un mismo ser de lo nuevo y lo antiguo, lo extraordinario, sobrenatural y ambivalente es la interpretación que captamos en Viaje al reino de los deseos de las épocas en transición, en las que, las nuevas ideas inyectan de energía y de valor las antiguas para remozar lo existente. 
Resulta, por lo tanto, muy significativo que encontremos reunidos, en un mismo texto, un haz de intertextos que apuntan hacia la creación, la renovación y la transformación, pero también, hacia la destrucción y la muerte.

\section{Bibliografía}

Amoretti, María. 1992. Diccionario de términos asociados en teoría literaria. San José: Editorial de la Universidad de Costa Rica.

Bataillon, Marcel. 1964. Varía lección de clásicos españoles. Madrid: Editorial Gredos.

Biblia. Versión popular. 1979. México: Soc. Bíblicas.

Cros, Edmond. 1980. Ideología y estética textual. Madrid: Cupso Editorial.

1986. Literatura, ideología y sociedad. Madrid: Gredos.

1986. "Reformuler la lecture que Baktine fait du Quichotte". Sociocriticism. Vol. IV, (8).

Chen Sham, Jorge. 1994. "El intertexto cervantino en un texto dieciochesco español: El fray Gerundio de Campazas”. Káñina. Vol. XVIII(2).

Curtius, Ernest R. 1975. Literatura europea y literatura latina. (tomos I y II) México: Fondo de Cultura Económica.

Cervantes de, Miguel. 1989. El ingenioso hidalgo don Quijote de la Mancha. Trigésima quinta edición. Madrid: Espasa-Calpe.

De Lope, Monique. 1988. "Bakhtine et la littérature médiévale approche critique." Sociocritisism. Vol. IV (8).

Herra, Rafael Ángel. 1992. Viaje al reino de los deseos. San José: Editorial de la Universidad de Costa Rica.

Le Goff, Jaques. 1986. Lo maravilloso y lo cotidiano en el Occidente medieval. México: Gedisa.

Maetzu, R. Don Quijote, Don Juan y La Celestina. Madrid: Contemporánea-Calpe.

Rey Hazas, Antonio. 1982. "Introducción de la novela del Siglo de Oro. I (Formas de narración idealista)". Edad de Oro. Vol. I. 